\title{
PENGARUH SOSIALISASI PEMERINTAH DAN KEPEMIMPINAN LURAH TERHADAP KESADARAN MASYARAKAT MEMBAYAR PAJAK BUMI DAN BANGUNAN DI KELURAHAN SENDANGSARI, PAJANGAN, BANTUL, DAERAH ISTIMEWA YOGYAKARTA
}

\author{
Felix Supriasto \\ Program Studi Akuntansi, Fakultas Ekonomi \\ Universitas Sarjanawiyata Tamansiswa \\ supriastofelix@yahoo.com
}

\begin{abstract}
This research was conducted to test the effect of a Government socialization variables and the leadership of the head of the tax paying public awareness of Earth and the buildings in the Sendangsari village, Pajangan, Bantul, Yogyakarta. This research use the dependent variable i.e. public awareness while the independent variable i.e. socializing the Government and the leadership of the head. The sampling technique used was purposive sampling. Purposive sampling technique (sample aims) is the technique of sampling conducted by taking samples and populations based on a certain criteria. Samples are only taken on the territory of Sendangsari Village, Pajangan, Bantul, Yogyakarta. Data collection procedure using a questionnaire which was distributed for Community taxpayers are filled by private persons. Analytical techniques used are multiple regression with SPSS 16.0 tools.

Based on the analysis of the data and the results of hypothesis testing on this research it can be concluded that the socialization of Government and the leadership of the head of influential positive significantly to the level of community awareness of paying taxes and the buildings, the ability of the regression equations in this research, to explain the magnitude of the variations that occur in variable $86.4 \%, 13.6 \%$ while explained by other variables not described by the researchers.
\end{abstract}

Key words: Socialization of the Government, the leadership of the head, and the awareness of paying taxes and building.

\section{PENDAHULUAN}

Tujuan pembangunan nasional bangsa Indonesia adalah untuk mencapai masyarakat adil dan makmur, merata baik material maupun spiritual berdasarkan Pancasila dan Undang-Undang Dasar 1945. Dalam usaha mencapai tujuan pembangunan tersebut, dilakukan pendayagunaanaparatur pemerintah, yang pelaksanaan dan penggunaannya juga diperlukan adanyapengawasan yang efektif dan efisien agar pembangunan nasional berjalan dengan baik. Pendayagunaan aparatur pemerintah sangat penting dalam pengelolaan pendapatan untuk menggali sumber pendapatan atau dana yang memadai guna membiayai pembangunan. Adapun sumbersumber penerimaan berasal dari luar negeri dan dalam negeri. Salah satu contoh penerimaan yang berasal dari dalam negeri yang sangat penting dan potensial sekali untuk membiayai pembangunan nasional adalah dari sektor pajak, khususnya Pajak Bumi dan Bangunan. Akan tetapi perlu 
adanya kinerja yang baik dari pemerintah, khususnya pemerintah tingkat desa yang langsung berhubungan dengan masyarakat agar penerimaan dari sektor pajak dapat maksimal, selainj itu juga kesadaran masyarakat membayar pajak juga sangat penting dari besar kecilnya penerimaan pajak.

Rumusan Masalah:

1. Bagaimana sosialisasi pemerintah dalam pemungutan dan tata cara pembayaran Pajak Bumi dan Bangunan kepada masyarakat di Kelurahan Sendangsari, Pajangan, Bantul, Daerah Istimewa Yogyakarta?

2. Bagaimana pengaruh kepemimpinan Lurah terhadap kesadaran masyarakat dalam membayar Pajak Bumi dan Bangunan di Kelurahan Sendangsari, Pajangan, Bantul, Daerah Istimewa Yogyakarta?

3. Seberapa besarkah pengaruh sosialisai pemerintah dan kepemimpinan Lurah terhadap kesadaran masyarakat dalam membayar Pajak Bumi dan Bangunan di Kelurahan Sendangsari, Pajangan, Bantul, Daerah Istimewa Yogyakarta?

\section{LANDASAN TEORI DAN HIPOTESIS}

Pajak merupakan iuran rakyat kepada kas negara berdasarkan Undang-undang yang dapat dipaksakan dengan tiada mendapat jasa timbal (kontraprestasi) yang langsung dapat ditujukan dan yang digunakan untuk membayar pengeluaran umum (Mardiasmo, 2006). Pajak Bumi dan Bangunan merupakan pajak yang bersifat kebendaan dalam arti besarnya pajak terutang ditentukan oleh keadaan objek pajak yaitu bumi atau tanah dan bangunan, keadaan subjek pajak (siapa yang membayar) tidak ikut menentukan besarnya pajak (Mardiasmo, 2002).

Sosialisasi merupakan proses belajar seorang anak untuk menjadi anggota yang berpartisipasi dalam masyarakat. Yang dipelajari dalam proses sosialisasi adalah peran, nilai, dan norma sosial (Sunarto,
2000). Untuk meningkatkan atau menimbulkan kesadaran akan kewajiban dalam hal pembayaran pajak diperlukan suatu sosialisasi. Sosialisasi dilakukan sekiranya dapat langsung mengenai sasaran yaitu wajib pajak sehingga diharapkan mereka sadar akan kewajibannya. Berdasarkan uraian di atas, dapat ditarik hipotesis sebagai berikut.

H1 : Sosialisasi pemerintah berpengaruh positif terhadap kesadaran masyarakat membayar pajak bumi dan bangunan.

Kepemimpinan merupakan suatu proses mempengaruhi dalam menentukan tujuan organisasi, memotivasi perilaku pengikut untuk mencapai tujuan, mempengaruhi untuk memperbaiki kelompok dan budayanya (Rivai dan Mulyadi, 2009). kepemimpinan adalah sebagai tindakan atau upaya untuk memotivasi atau mempengaruhi orang lain agar mau bekerja atau bertindak ke arah pencapaian tujuan organisasi yang telah ditetapkan atau kepemimpinan merupakan tindakan membuat sesuatu menjadi kenyataan. (Kusnadi, 2005).

H2 : kepemimpinan lurah berpengaruh positif terhadap kesadaran masyarakat membayar Pajak Bumi dan Bangunan.

Kesadaran membayar pajak merupakan suatu bentuk moral yang memberikan kontribusi kepada negara untuk menunjang pembangunan negara dan berusaha untuk mentaati semua peraturan yang telah ditetapkan oleh negara serta dapat dipaksakan kepada wajib pajak (Nugroho, 2012). Kesadaran wajib pajak adalah suatu kondisi dimana wajib pajak mengetahui, memahami dan melaksanakan ketentuan perpajakan yang berlaku denganbenar, sukarela, dan bersungguh-sungguh untuk memenuhi kewajiban pajaknya (Fikriningrum, 2012).

H3 : Sosialisasi pemerintah dan kepemimpinan lurah berpengaruh positif terhadap kesadaran masyarakat membayar pajak bumi dan bangunan. 


\section{Kerangka konseptual}

\section{Gambar 1 \\ Kerangka konseptual}

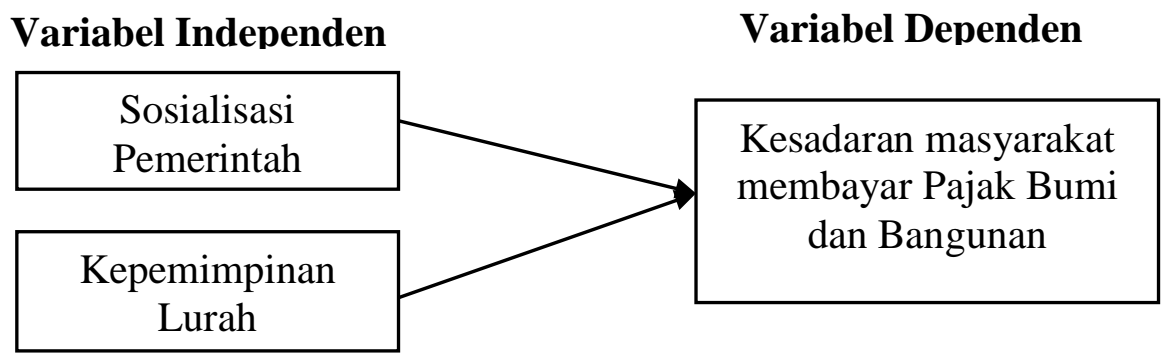

Kerangka konseptual menjelaskan bahwa kesadaran masyarakat dalam membayar Pajak Bumi dan Bangunan dipengaruhi oleh sosialisasi dari pemerintah mengenai Pajak Bumi dan Bangunan.Lurah sebagai bagian dari pemerintah yang berhadapan langsung dengan masyarakat mendapat peran yang sangat besar dalam menumbuhkan kesadaran masyarakat membayar Pajak Bumi dan Bangunan.

\section{METODE PENELITIAN}

Jenis penelitian yang digunakan dalam penelitian ini adalah penelitian kuantitatif. Data yang digunakan dalam penelitian ini merupakan data primer. Pengumpulan data dilkukan dengan menyebarkan kuesioner sehingga mendapatkan informasi mengenai sosialisasi pajak, kepemimpinan lurah, dan kesadaran masyarakat dalam membayar Pajak Bumi dan Bangunan.

Penelitian ini dilakukan di Kelurahan Sendangsari, Kecamatan Pajangan, Kabupaten Bantul, Daerah Istimewa Yogyakarta. Adapun Kecamatan Pajangan terdiri atas 18 pedukuhan yakni Kabrokan Kulon, Kabrokan Wetan, Kamijoro, Manukan, Jaten, Mangir Lor, Mangir Tengah, Mangir Kidul, Kunden, Benyo, Jetis, Beji Kulon, Beji Wetan, Dadapbong, Gupak Warak, Kayen, Krebet, dan Panjangan.

Populasi merupakan wilayah generalisasi yang terdiri atas subyek dan obyek yang mempunyai kualitas dan karakteristik tertentu yang ditetapkan oleh peneliti untuk dipelajari kemudian ditarik kesimpulannya (Sugiyono, 2003). Dalam penelitian ini yang menjadi populasi adalah masyarakat lingkungan 18 pedukuhan di Kelurahan Sendangsari.

Sampel merupakan bagian dari jumlah dan karakteristik yang dimiliki populasi tersebut (Sugiyono, 2003). Sampel yang diambil menggunakan teknik purposive sampling. Teknik purposive sampling (sampel bertujuan) merupakan teknik pengambilan sampel yang dilakukan dengan mengambil sampel dan populasi berdasarkan suatu kriteria tertentu. Kriteria yang digunakan dapat berdasarkan pertimbangan tertentu atau jatah tertentu (Jogiyanto, 2008).

Teknik pengumpulan data penelitian yang dipakai yaitu purposive sampling. Data yang digunakan dalam penelitian ini adalah data primer. Pengumpulan data Primer yakni pengumpulan data yang dilakukan secara langsung ke lokasi penelitian untuk mendapatkan data yang lengkap dan berkaitan dengan masalah yang diteliti (Supardi, 2006).

\section{HASIL DAN PEMBAHASAN \\ Hasil Uji Statistik Deskriptif}

Variabel yang digunakan dalam penelitian ini adalah sistem sosialisasi pemerintah, kepemimpinan lurah, dan kesadarana masyarakat pada wajib pajak akan diuji secara statistik deskriptif dengan 
nilai minimum sebagai nilai terendah dan masing-masing variabel. maksimum sebagai nilai tertinggi untuk

Tabel 1

Statistik Deskripsi

\begin{tabular}{lccccc}
\hline & N & Minimum & Maximum & Mean & Std. Deviation \\
\hline SOSIALISASI PEMERINTAH & 94 & 26.00 & 41.00 & 35.8830 & 3.50071 \\
KEPEMIMPINAN LURAH & 94 & 27.00 & 43.00 & 37.6277 & 3.63964 \\
KESADARAN WAJIB PAJAK & 94 & 46.00 & 67.00 & 59.3617 & 4.42343 \\
Valid N (listwise) & 94 & & & & \\
\hline
\end{tabular}

Sumber: Data primer yang diolah

Tabel 1 menjelaskan bahwa sosialisasi pemerintah dengan rata-rata total sebesar 35.8830, dengan standar deviasi sebesar 3.50071. Ini berarti bahwa sebagian responden cenderung menjawab setuju untuk pertanyaan yang diajukan berkaitan dengan masalah sosialisasi pemerintah mengenai pajak. Begitu juga dengn variabel kepemimpinan lurah dengan rata-rata total 37.6277 dengan standar deviasi sebesar 3.63964. Variabel tingkat kesadaran masyarakat membayar Pajak Bumi dan Bangunan dengan rata-rata total sebesar 59.3617 dengan standar deviasi sebesar 4.42343 menunjukkan bahwa tingkat kesadaran masyarakat dalam penelitian ini sebesar $51 \%$. Ini berarti sebagian responden menjawab setuju untuk pertanyaan yang diajukan berkaitan dengan tingkat kesadaran masyarakat membayar Pajak Bumi dan Bangunan. Nilai standar deviasi masingmasing variabel lebih kecil dari nilai rata-rata maka data yang diperoleh dari lapangan dapat direpresetasikan ke populasi.

\section{Hasil Uji Kualitas Data}

\section{a. Hasil Uji Validitas Data}

Hasill uji validitas dari tiga variabel yaitu sosialisasi pemerintah, kepemimpinan lurah dan kesadaran masyarakat. Dalam penelitian ini telah di uji validitas hasil kuesioner yang telah disebarkan kepada responden yaitu item pertanyaan dengan variabel sosialisasi pemerintah, kepemimpinan lurah dan kesadaran masyarakat.

Tabel 2

Hasil Pengujian Validitas

\begin{tabular}{clccc}
\hline No & $\begin{array}{l}\text { Variabel / } \\
\text { Butir Pertanyaan }\end{array}$ & $\begin{array}{c}\text { R hitung } \\
\text { (Corrected Item-Total } \\
\text { Correlation) }\end{array}$ & r tabel & Keterangan \\
\hline 1 & Sosialisasi Pemerintah & .317 & .207 & Valid \\
& Butir1.1 & .257 & .207 & Valid \\
& Butir1.2 & .371 & .207 & Valid \\
& Butir1.3 & .267 & .207 & Valid \\
& Butir1.4 & .219 & .207 & Valid \\
& Butir1.5 & .244 & .207 & Valid \\
& Butir1.6 & .679 & .207 & Valid \\
& Butir1.7 & .590 & .207 & Valid \\
& Butir1.8 & .390 & .207 & Valid \\
& Butir1.9 & .475 & .207 & Valid \\
& Butir1.10 & .375 & .207 & Valid \\
& Butir1.11 & & & \\
2 & Kepemimpinan Lurah & .367 & .207 & Valid
\end{tabular}




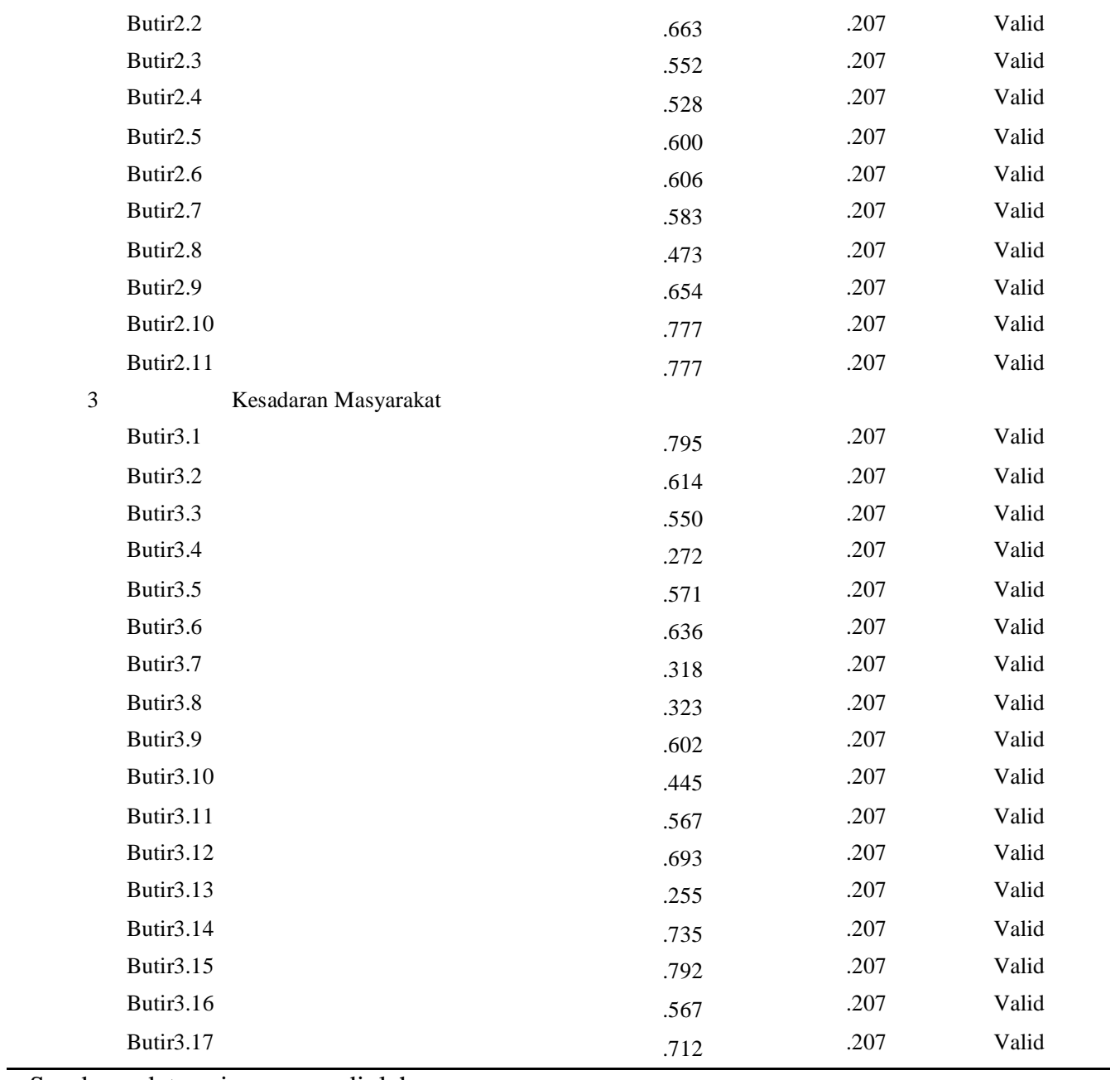

Sumber : data primer yang diolah

\section{b. Hasil Uji Reliabilitas Data}

Tabel 3

Hasil Pengujian reliabilitas

\begin{tabular}{lcc}
\hline Variabel & Cronbach Alpha & Keterangan \\
\hline Sosialisai Pemerintah & .699 & Reliabel \\
Kepemimpinan Lurah & .757 & Reliabel \\
Kesadaran Wajib Pajak & .747 & Reliabel \\
\hline
\end{tabular}

Tabel 3 menunjukkan mengenai uji reliabilitas dimana suatu instrumen cukup dapat dipercaya untuk digunakan sebagai alat pengumpulan data karena instrumen sudah baik atau suatu angket dikatakan reliabel jika jawaban responden konsisten. Tingkat reliabilitas dapat dijelaskan bahwa sosialiasi pemerintah terhadap kesadaran masyarakat membayar Pajak Bumi dan Bangunan dari 11 item pertanyaan dan nilai Cronbach's Alpha sebesar 0,699, artinya sosialisasi memiliki nilai reliabilitas yang handal. Begitu juga dengan tingkat reliabilitas kepemimpinan lurah terhadap kesadaran masyarakat membayar Pajak Bumi dan Bangunan dari 11 item pertanyaan dan nilai Cronbach's Alpha sebesar 0,757 artinya kepemimpinan lurah memiliki nilai reliabilitas yang handal dan memadai. Tingkat reliabilitas dapat dijelaskan bahwa tingkat pemahaman tentang Pajak Bumi dan Bangunan dari 17 item pertanyaan dan nilai sebesar 0,747 artinya tingkat pemahaman 
tentang Pajak Bumi dan Bangunan memiliki nilai reliabilitas yang handal dan memadai.

\section{Hasil Uji Asumsi Klasik}

a. Hasil Uji Normalitas

Uji normalitas data dilakukan untuk melihat bahwa suatu data terdistribusi secara normal atau tidak. Uji normalitas data dilakukan dengan menggunakan histogram standardized residual dan P-Plot standardized residual. Apabila histogram terdistribusi normal maka data dinyatakan normal, sementara itu apabila P-Plot

Histogram

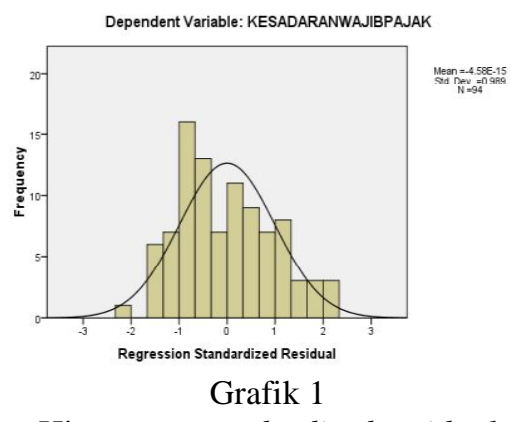

Histogram standardized residual membentuk garis diagonal maka data dinyatakan normal (Ghozali, 2005). Pada gambar 1.1 dan 1.2 berikut ini dapat dilihat histogramstandardized residualdan P-Plot standardized residual.

Berdasarkan gambar grafik 1 dan 2 dapat diketahui bahwa histogram standardized residual dan P-Plot standardized residual menunjukkan pola data distribusi normal. Gambar 2 terlihat titik-titik menyebar disekitar garis diagonal, maka regresi memenuhi persamaan normalitas.

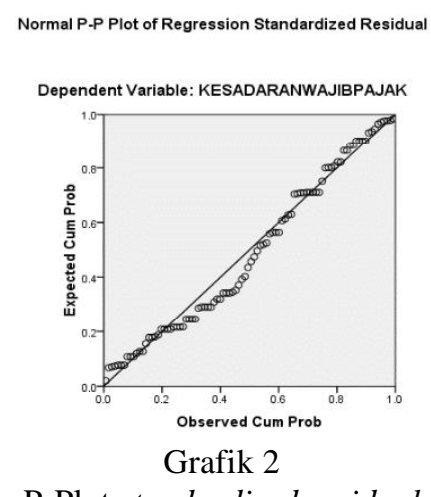

P-Plot standardized residual

maka disimpulkan bahwa data terdistribusi normal.

Uji statistik lain yang dapat digunakan untuk menguji normalitas residual adalah dengan uji Kolmogorov-Smirnov (K-S).

Tabel 4

One-Sample Kolmogorov-Smirnov Test

\begin{tabular}{llr}
\hline & & Unstandardized Residual \\
\hline $\mathrm{N}$ & Mean & 94 \\
Normal Parameters $^{\mathrm{a}}$ & Std. Deviation & .0000000 \\
& Absolute & 1.61178937 \\
Most Extreme Differences & Positive & .107 \\
& Negative & .107 \\
Kolmogorov-Smirnov Z & & -.057 \\
Asymp. Sig. (2-tailed) & & 1.033 \\
a. Test distribution is Normal. & & .236
\end{tabular}

berdasarkan pengolahan data dengan bantuan SPSS 16, data dalam penelitian ini memenuhi normalitas. Hal tersebut dibuktikan dengan nilai signifikan lebih besar dari 0,05 yaitu 0,236 .

\section{b. Hasil Uji Multikolonieritas}

Tabel 5 menjelaskan mengenai hasil uji multikolonieritas, dimana tidak terdapat problem multikol pada model persamaan 
regresi dan dapat digunakan dalam penelitian ini.

Tabel 5

Uji Multikolonieritas

\begin{tabular}{lcc}
\hline Model & $\begin{array}{c}\text { Collinearity Statistics } \\
\text { Tolerance }\end{array}$ & VIF \\
\hline 1 (Constant) & & \\
SOSIALISASIPEMERINTAH & .531 & 1.885 \\
KEPEMIMPINANLURAH & .531 & 1.885 \\
a. Dependent Variable: res_2 & & \\
\hline
\end{tabular}

Berdasarkan tabel 5 terlihat bahwa nilai tolerance menunjukkan angka 1 dan nilai variance inflatuion factor (VIF) disekitar angka 1 untuk setiap variabel, yang ditunjukkan dengan nilai tolerance masingmasing variabel 0,531 serta VIF sebesar 1,885 untuk masing-masing variabel, baik variabel kepemimpinan lurah maupun variabel sosialisasi pemerintah. Hal ini dapat disimpulkan bahwa tidak terjadi multikolonieritas dalam persamaan regresi berganda.

\section{c. Hasil Uji Heteroskedastisitas}

Grafik 3 menjelaskan mengenai ada tidaknya heteroskedastisitas dilakukan dengan melihat ada tidaknya pola tertentu pada grafik scatterplot antara SRESID dan ZPRED. Hal ini dapat dilihat dari grafik 1.3.

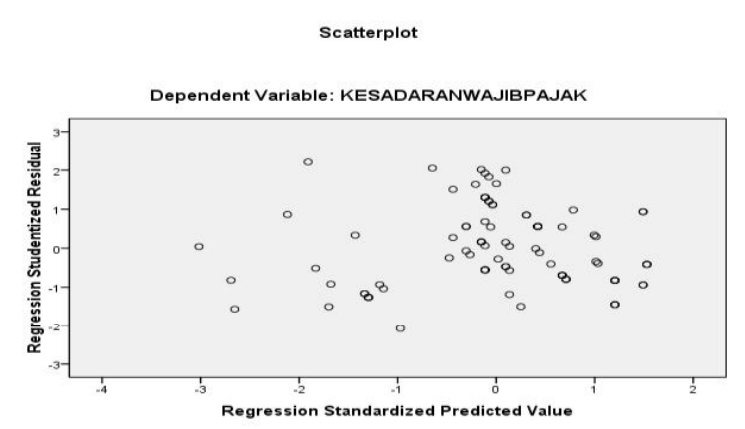

Grafik 3

Hasil Uji Heteroskedastisitas

Berdasarkan grafik 3 menunjukkan bahwa data tersebar di atas dan di bawah angka 0 (nol) pada sumbu Y dan tidak terdapat suatu pola yang jelas pada penyebaran tersebut. Hal ini berarti tidak terjadi heteroskedastisitas pada model persamaan regresi, sehingga model regresi layak digunakan untuk memprediksi tingkat kesadaran masyarakat membayar Pajak Bumi dan Bangunanberdasarkan variabel yang mempengaruhinya, yaitu sosialisasi pemerintah dan kepemimpinan lurah.

Untuk lebih memperkuat bahwa tidak terjadi heteroskedastisitas maka dilakukan Uji Glejser. Uji Glejser dilakukan dengan meregresi variabel-variabel bebas dalam persamaan regresi dengan nilai residual sebagai variable terikatnya.

\begin{tabular}{cccc}
\multicolumn{3}{c}{ Tabel 6 } \\
Hasil Uji Glejser \\
\hline \multicolumn{2}{c}{ Model } & $\mathrm{T}$ & Sig. \\
\hline $1 \quad$ (Constant) & 2.594 & .011 \\
& SOSIALISASIPEMERINTAH & 1.681 & .096 \\
& KEPEMIMPINANLURAH & -2.625 & .010 \\
& &
\end{tabular}

Hasil uji Glejser seperti yang terlihat pada Tabel 6 diketahui bahwa semua variabel bebas dengan absolut residual lebih dari 0,05 , maka tidak terjadi heteroskedastisitas..

1. Hasil Uji Hipotesis

Pengujian hipotesis dilakukan dengan menggunakan model analisis berganda, yaitu:

\section{a. Hasil Uji Simultan (Uji F) \\ Uji simultan digunakan untuk} mengetahui pengaruh semua variabel independen yang dimasukkan dalam model regresi secara simultan terhadap variabel dependen yang diuji pada tingkat signifikan 0,05. Hasil uji statistik F dapat dilihat pada 7. 
Tabel 7

Hasil Uji Simultan (Uji F) ANOVA $^{\mathbf{b}}$

\begin{tabular}{ccccccc}
\hline & Model & Sum of Squares & Df & Mean Square & F & Sig. \\
\hline 1 & Regression & 1578.101 & 2 & 789.050 & 297.198 & $.000^{\mathrm{a}}$ \\
& Residual & 241.601 & 91 & 2.655 & & \\
& Total & 1819.702 & 93 & &
\end{tabular}

a. Predictors: (Constant), KEPEMIMPINANLURAH, SOSIALISASIPEMERINTAH

b. Dependent Variable: KESADARANWAJIBPAJAK

Hasil Uji Hipotesis 3:

Pengaruh sistem sosialisasi pemerintah dan kepemimpinan lurah terhadap kesadaran masyarakat membayar Pajak Bumi dan Bangunan.

Hasil uji hipotesis 3 dapat dilihat pada tabel di atas, nilai $\mathrm{F}$ diperoleh sebesar 297,198 dengan tingkat kesalahan 5\%, dimana $\mathrm{F}$ tabel $=3,11$ ternyata $\mathrm{F}$ hitung $>\mathrm{F}$ tabel $(297,198>3,11)$, dengan demikian $F$ hitung > F tabel sehingga $\mathrm{HO}$ ditolak dan $\mathrm{Ha}$ diterima, ini menunjukkan bahwa secara simultan antara sosialisasi pemerintah dan kepemimpinan lurah berpengaruh terhadap kesadaran masyarakat membayar Pajak Bumi dan Bangunan.

\section{b. Hasil Uji t Statistik}

Uji $t$ statistik digunakan untuk mengetahui pengaruh masing-masing variabel independent secara individual terhadap dependen yang diuji pada tingkat signifikasi 0,05 , dimana $t$ tabel $=3,11$. Hasil uji statistik t dapat dilihat pada tabel 8 .

Tabel 8

Hasil Uji T Statistik

\begin{tabular}{lcccccc}
\hline & \multicolumn{2}{c}{$\begin{array}{l}\text { Unstandardized } \\
\text { Coefficients }\end{array}$} & \multicolumn{2}{c}{$\begin{array}{c}\text { Standardized } \\
\text { Coefficients }\end{array}$} & & \\
Model & B & Std. Error & Beta & $\mathrm{t}$ & Sig. \\
\hline 1 (Constant) & 15.229 & 1.902 & & 8.005 & .000 \\
SOSIALISASI PEMERINTAH & .158 & .066 & .125 & 2.383 & .019 \\
KEPEMIMPINAN LURAH & 1.022 & .064 & .841 & 16.040 & .000 \\
\hline
\end{tabular}

a. Dependent Variable: KESADARANWAJIBPAJAK

\section{Hasil Uji Hipotesis 1:}

Pengaruh sosialisasi pemerintah terhadap kesadaran masyarakat membayar Pajak Bumi dan Bangunan.

Berdasarkan tabel di atas, dapat dilihat bahwa nilai thitung untuk variabel sosialisasi pemerintah (X1) terhadap kesadaran masyarakat (Y) sebesar 2,383, berarti $t$ hitung $>\mathrm{t}$ tabel $(2,383>3,11)$, memiliki tingkat signifikansi 0,019 karena tingkat signifikasi lebih kecil dari 0,05 , hal ini membuktikan bahwa Ho ditolak dan $\mathrm{Ha}$ diterima, ini menunjukkan bahwa variabel sosialisasi pemerintah berpengaruh positif signifikan terhadap tingkat kesadaran masyarakat membayar Pajak Bumi dan Bangunan.
Hasil Uji Hipotesis 2:

Pengaruh kepemimpinan lurah terhadap kesadaran masyarakat membayar Pajak Bumi dan Bangunan.

Hasil pengujian variabel kepemimpinan lurah (X2) terhadap tingkat kesadaran masyarakat (Y) sebesar 16,040, berarti $\mathrm{t}$ hitung > $\mathrm{t}$ tabel $(16,040>3,11)$, memiliki tingkat signifikansi 0,000 karena tingkat signifikansi lebih kecil dari 0,05, hal ini membuktikan bahwa Ho ditolak dan $\mathrm{Ha}$ diterima, ini menunjukkan bahwa variabel kepemimpinan lurah berpengaruh positif terhadap tingkat kesadaran masyarakat membayar Pajak Bumi dan Bangunan.

Berdasarkan tabel di atas, maka diperoleh persamaan regresi sebagai berikut. 
$\mathrm{Y}=8,005+2,383 \mathrm{X} 1+16,040 \mathrm{X} 2+\mathrm{e}$

Konstanta (alpha) sebesar 8,005 memberi pengertian jika sosialisasi pemerintah dan kepemimpinan lurah tidak ada atau sama dengan nol (0), maka besarnya tingkat kesadaran masyarakat membayar Pajak Bumi dan Bangunan di kelurahan Sendangsari, Pajangan, Bantul, Daerah Istimewa Yogyakarta sebesar 8,005 satuan. Variabel sosialisasi pemerintah (X1) sebesar 2,383 jika terjadi peningkatan sosialisasi pemerintah mengenai pajak di Kelurahan Sendangsari, Pajangan, Bantu, Daerah Istimewa Yogyakarta sebesar satu (1) satuan, maka akan terjadi peningkatan kesadaran masyarakat membayar pajak sebesar 2,383 satuan dengan asumsi variabel lainnya tidak dilakukan atau sama dengan nol (0). Demikan juga untuk variabel kepemimpinan lurah (X2) sebesar 16,040, setiap ada penambahan satu (1) satuan maka akan terjadi peningkatan kesadaran membayar Pajak Bumi dan Bangunan sebesar 16,040.

\section{c. Uji Koefisien Determinasi}

Tabel 9 menjelaskan mengenai besarnyapengaruh sosialisasi pemerintah (X1) dan kepemimpinan lurah (X2) terhadap kesadaran masyarakat membayar Pajak Bumi dan Bangunan (Y) di Kelurahan Sendangsari, Pajangan, Bantul, Daerah Istimewa Yogyakarta.

\begin{tabular}{|c|c|c|c|c|}
\hline \multicolumn{5}{|c|}{$\begin{array}{c}\text { Tabel } 9 \\
\text { Hasil Uji Koefisien Determinasi }\end{array}$} \\
\hline Model & $\mathrm{R}$ & R Square & $\begin{array}{l}\text { Adjusted } \\
\text { R Square }\end{array}$ & $\begin{array}{l}\text { Std. Error of the } \\
\text { Estimate }\end{array}$ \\
\hline 1 & $.931^{\mathrm{a}}$ & .867 & .864 & 1.62941 \\
\hline \multicolumn{5}{|c|}{$\begin{array}{l}\text { a. Predictors: (Constant), KEPEMIMPINANLURAH, } \\
\text { SOSIALISASIPEMERINTAH }\end{array}$} \\
\hline \multicolumn{5}{|c|}{ b. Dependent Variable: KESADARANWAJIBPAJAK } \\
\hline
\end{tabular}

Tabel 9 menunjukkan bahwa nilai Adjusted R Square sebesar 0,864 atau 86,4\% menunjukkan bahwa variabel kesadaran masyarakat dapat dipengaruhi oleh sosialisasi pemerintah dan kepemimpinan lurah sebesar $86,4 \%$ sedangkan sisanya sebesar $13,6 \%$ dipengaruhi oleh faktor-faktor lain yang tidak disebutkan dalam penelitian ini.

\section{SIMPULAN DAN SARAN}

Berdasarkan analisis data dan hasil pengujian hipotesis pada penelitian ini dapat disimpulkan bahwa sosialisasi pemerintah dan kepemimpinan lurah berpengaruh positif signifikan terhadap tingkatkesadaran masyarakat membayar Pajak Bumi dan Bangunan. Kemampuan persamaan regresi dalam penelitian ini, untuk menjelaskan besarnya variasi yang terjadi pada variabel terikat sebesar $86,4 \%$ sementara $13,6 \%$ dijelaskan oleh variabel lain yang tidak dijelaskan oleh peneliti.

Untuk selanjutnya, peneliti mengajukan saran sebagai berikut.

1. Perlunya peningkatan sosialiasasi kepada masyarakat tentang peraturan perpajakan khususnya Pajak Bumi dan Bangunan yang berlaku saat ini dan pentingnya pajak bagi negara dalam rangka meningkatkan pengetahuan masyarakat dan meningkatkan penerimaan pajak negara guna pembiayaan pembangunan negara.

2. Pemerintah atau petugas pajak memberikan kemudahan kepada masyarakat untuk mendapatkan informasi mengenai pajak khususnya Pajak Bumi dan Bangunan, baik itu mengenai pentingnya pajak sampai dengan bagaimana mekanisme pembayaran pajak.

3. Pemerintahatau petugas pajak perlu meningkatkan kualitas pelayanan pajak serta mempunyai mental yang kuat dalam melayani wajb pajak dengan sebaik-baiknya.

4. Lurah memberikan pola kepemimpinan yang dapat memberikan motivasi kepada masyarakat untuk meningkatkan kesadaran masyarakat dalam membayar pajak, khususnya Pajak Bumi dan Bangunan.

5. Penelitian selanjutnya dapat dilakukan di daerah- daerah lain. 


\section{JURNAL AKUNTANSI. VOL.2 NO.2 DESEMBER 2014}

\section{REFERENSI}

Fikriningrum, Winda Kurnia, 2012. Skripsi : "Analisis Faktor-faktor yang Mempengaruhi Wajib Pajak Orang Pribadi dalam Memenuhi Kewajiban Membayar Pajak (Studi Kasus Pada Kantor Pelayanan Pajak Pratama Semarang Candisari)". Semarang.

Ghozali, Imam. 2005. Aplikasi Analisis Multivariate dengan Program SPSS. Edisi Ketiga. Badan Penerbit UNDIP. Semarang.

Jogiyanto. 2008. Metodologi Penelitian Sistem Informasi. Yogyakarta : Penerbit Andi.

Kusnadi dkk. 2005. Pengantar Manajemen (Konsepsual \& Perilaku). Malang : Univeritas Brawijaya.

Mardiasmo. 2002. Perpajakan. Yogyakarta: Penerbit Andi.
2006. Perpajakan. Edisi Revisi. Yogyakarta : Penerbit Andi.

Nugroho, Rahmad Adi, 2012. Skripsi : "Faktor-Faktor yang Mempengaruhi Kemauan Membayar Pajak dengan Kesadaran Membayar Pajak Sebagai Variabel Intervening (Studi Kasus Wajib Pajak Orang Pribadi Yang Melakukan Pekerjaan Bebas Yang Terdaftar Di KPP Pratama Semarang emarang.

Rivai dan Mulyadi. 2009. Kepemimpinen dan Perilaku Organisasi. Edisi ketiga.Jakarta : Rajawali Perss.

Sugiyono. 2003. Metode Penelitian Administrasi. Alfabeta. Bandung.

Supardi. 2006. Metodologi Penelitian. Mataram : Yayasan Cerdas Press. 